\title{
Praetoryanist Liderlik Ölçeğinin Geliştirilmesi
}

\author{
Ali BALTACI*
}

Öz

Praetoryanizm, bir kişi veya grubun, bașka bir kiși veya bir grubun iyiliğini veya kendi çıkarlarını düşünerek onların özgürlüklerine müdahale etmesi ve onları kontrol altına almasıdır. Praetoryanist liderler, çalışanlarının hayatlarının her alanında kontrol sahibi olma niyetindedirler. Bu karakterle onlar, iş yaşamını çekilmez kılabilirler. $\mathrm{Bu}$ çalışmanın amacı yöneticilerin praetoryanist liderlik davranışlarına sahip olma düzeylerine ilişkin kullanılabilecek bir veri toplama aracı geliștirmektir. Araştırmanın ana çalıșma grubu ise, İstanbul'daki resmi okullarda görev yapan 983 öğretmenden oluşmaktadır. Ölçeğin faktörlerini belirleyebilmek için Açımlayıcı Faktör analizi kullanılmıștır. Güvenilirliği belirleyebilmek için Cronbach's Alfa ve Bileşik Güvenilirlik katsayısı kullanılmıştır. Ölçeğin yapı geçerliği, iki aşamalı hiyerarşik doğrulayıcı faktör analizi ile test edilmiştir. İki aşamalı yaklaşımda, öncelikle ölçme modeli, ardından yapılandırılmış model incelenmiștir. Bu çalıșmalara ek olarak her bir alt ölçeğin açıklanan ortalama varyansı hesaplanarak modelin birleșim ve ayrışım geçerliği de belirlenmiștir. Sonuç olarak Praetoryanist Liderlik Ölçeğinin, üç boyuttan oluştuğu (yönlendiricilik, kısıtlayıcılık, yetkecilik) belirlenmiştir. Ölçek yöneticilerdeki praetoryanist liderlik düzeylerine ilişkin algıyı ölçebilecek niteliktedir. Ayrıca ölçeğin yönetim bilimleri alanyazınına önemli bir katkı sunacağı düşünülmektedir.

Anahtar Kelimeler: Praetoryanizm, Praetoryanist Liderlik, Praetoryanist Liderlik Ölçeği, Geçerlik, Güvenirlik

\section{The Development of the Praetorianistic Leadership Scale}

\begin{abstract}
Praetorianism is when a person or group interferes with their liberties and takes them under control by considering the goodness or interests of another person or group. Praetorianistic leaders intend to have control over all aspects of their employees' lives. With this character, they can make business life unbearable. This study aims to develop a data collection tool that can be used regarding the level of praetorianistic leadership behaviors of managers. The main working group of the study consisted of 983 teachers working in public schools in Istanbul. Exploratory Factor Analysis was used to define the factors of the scale. Cronbach's Alpha and Compound Reliability coefficient were used to conclude reliability. The construct validity of the scale tested by two-stage hierarchical

\author{
Özgün Araştırma Makalesi (Original Research Article) \\ Geliş/Received: 01.07.2019 \\ Kabul/Accepted: 17.03 .2020 \\ DOI: https://dx.doi.org/10.17336/igusbd.594548
}

* Dr. Öğr. Üyesi, Mersin Üniversitesi, İslami İlimler Fakültesi, Felsefe ve Din Bilimleri Bölümü, Mersin, Türkiye, E-posta: alibaltaci@mersin.edu.tr ORCID ID https://orcid.org/0000-0003-2550$\underline{8698}$
\end{abstract}


Confirmatory Factor Analysis. In the two-stage approach, first the measurement model and then the structured model were examined. In addition to these studies, the explained mean-variance of each subscale was calculated and the validity of the combination and decomposition of the model was determined. As a result, the Praetorianistic Leadership Scale was consisting of three dimensions (restrictive, directive, and authoritarianism). The scale is capable of measuring the perception of the praetorianistic leadership levels in managers. Besides, the scale is thought to make an important contribution to the literature of management sciences.

Keywords: Praetorianism, Praetorianistic Leadership, Praetorianistic Leadership Scale, Validity, Reliability

\section{Giriş}

Yeni teknolojik gelişme ve yenileşmelerle birlikte küresel rekabet de gelişmiş ve çağımıza özgü bir belirsizlik durumu giderek örgüt çevrelerine hâkim olmaya başlamıştır. Böylesi bir belirsizliğin aktif olarak yönetilmesinin gerekliliği özellikle sosyal bilimler alanyazınında sıklıkla vurgulanmaktadır. Çağımıza özgü liderlik biçimlerinin geliştirilmesi ve örgütlerin bu yeni liderlik biçimleri ile yönetilmesi önem kazanmaktadır. Praetoryanizm de bu yeni liderlik anlayışlarından biri olarak ön plana çıkmaktadır. Özünde bir kişinin ne pahasına olursa olsun diğerlerini koruma ve kollama davranışlarını benimseyen praetoryanizm, örgüt çalışanları ve yöneticiler arasındaki ilişkilere odaklanmaktadır.

$\mathrm{Bu}$ çalışma esasen alanyazındaki liderlik stilleri arasında yer alan praetoryanist liderliğin ölçülmesinin gerekliliğinden doğmuştur. $\mathrm{Bu}$ çalışmanın amacl okul yöneticilerinin praetoryanist liderlik davranışlarına sahip olma düzeylerine ilișkin öğretmen görüşlerini belirlemede kullanılabilecek bir veri toplama aracı geliștirmektir. Alanyazında farklı türden ölçekler bulunsa da temel olarak geçerlik ve güvenirliği test edilmiş bir praetoryanist liderlik modelinin bulunmadığı belirlenmiștir. Bu araștırma ile bu açığın kapatılması hedeflenmiștir. İlerleyen bölümlerde praetoryanizm kavramı, praetoryanist liderlik ve önerilen praetoryanist liderlik ölçeğine ilişkin bölümler yer almaktadır.

\section{Yönetsel Bir Kavram Olarak Praetoryanizm}

Praetoryanizm, bir kişi veya grubun, başka bir kiși veya bir grubun iyiliğini veya kendi çıkarlarını düşünerek onların özgürlüklerine müdahale etmesi ve onları kontrol altına alması durumudur (Pion-Berlin ve Trinkunas, 2010). Genellikle siyaset bilimde antidemokratik bir eğilim (Uzgel, 2003) olarak tanımlanan, Latince "muhafız, lejyoner vb.", Arapça "rakib, murakib" anlamlara gelen praetoryan kelimesi, Roma İmparatorluğu döneminde, imparatoru korumakla görevli özel eğitimli muhafızlara verilen isimdir. Muhafızlar, imparatoru korurken, aynı zamanda ona çeşitli kararları almasında koşulsuz bir destek sunmaktadırlar. Praetoryanizm düşüncesi, devletin vatandaşlarını korumak ve onlara yardım sağlamak rolünü üstlendiği 'toplumsal refah' düșüncesinin bir sonucu olarak Roma İmparatorluğu döneminde ortaya çıkmıştır (Bowman, 2010). Praetoryanizm, bir kişinin, kendisi dıșındaki insanların iyiliği ya da yararına olabilecek durumlara odaklanarak yaşamlarına müdahil olma ve insanların istek ve düşüncelerini göz ardı ederek çeşitli kararlar alma veya düzenlemelere gitme durumudur (Haleem, 2003). Bu noktada herhangi bir kişiden habersiz olarak alınan kararlar ve düzenlemelerin o kişiler için en doğru tercih olacağı inancı da praetoryanizm kavramıyla birlikte incelenmektedir. Kavram, bir kişinin kendisi dışındaki kişileri veya başkalarının kendi 
öznel seçimlerini mantıksız veya uygunsuz görme ve olumsuz yöne eleştirme durumunu da içerir (Ben-Eliezer, 1997). Başkaları adına, onların iyiliği veya kendi salt çıkarları için hareket eden kişi ise praetoryanist olarak adlandırılmaktadır (Mahmud, 1993). Bir praetoryanistin belirgin özelliği, başkalarının da kendisi gibi düşünmesini ve koşulsuz olarak kendi doğrularına uymasını istemesidir. Kişiler arası ilişkilerde veya örgütsel davranış açısından praetoryanizmden bahsedebilmek için, praetoryanist davranıştan etkilenen bireyin özerk tercihlerinin sınırlandırılması ve çoğunlukla engellenmesi gereklidir (Baltacı, 2018a). Bu noktada Praetoryanizm, gerek zarardan kaçınma ve gerekse yararlı olma isteğiyle, başka birisinin seçimlerine, istek ve ihtiyaçları ile faaliyetlerine razı olmamak veya müdahale etmektir (Hen-Tov ve Gonzalez, 2011).

Praetoryanist, ilkin diğer kişilere sevecen bir șekilde yaklaşır; sonrasında onların çoğu hakkını göz ardı ederek onlar adına çeşitli eylemler sergiler (Hussain, 1976). Böylesi bir tutum, örgüt çalışanları için koruyucu ve kollayıcı bir durum olmaktan ziyade, önemli bir tahakküm durumu oluşturmaktadır. Bu yönüyle praetoryanizm, demokrasi karșıtı eylemler dizgesi veya karanlık karakter olarak da anılmaktadır (Shah, 2008; Uzgel, 2003). Çalışma hayatında sıklıkla karşılaşılan bir durum olan praetoryanizm, aynı zamanda önemli bir tartışma konusudur. Bu noktada örgütsel yaşamda birey özgürlükleri, özerklikler, başkalarının hakkına saygı, karşılıklı çıkarların yönetilmesi ve başkalarının yararı gibi uygulamalı etik tartışmalar sürmektedir (Di Tella, 2017).

\section{Praetoryanist Liderlik Kavramı}

Son dönemlerde örgüt alanyazınında yer almakta olan praetoryanist liderliğin tanımı ve kapsamı hakkında bir görüş birliği söz konusu olmamakla birlikte kavramın kökenleri militarist yönetim anlayışına dayanmaktadır (Ferguson, 2017). Praetoryanist liderlik, rütbeli bir askerin, ordu üzerindeki hâkimiyetini andırır. Asker figürüne olan saygı, bağlılık ve itaat gibi tutum ve davranışları temel alan praetoryanist liderlik, örgüt çalışanlarından örgüt lider ve yöneticilerine karşı askeri bir kontrolü meșru kılacak şekilde davranmalarını istemektedir (Peri, 2017). Praetoryanist liderlik, katı bir disiplin ve otoritenin çeşitli tutum ve davranışlarla uyumlaştırılması ve otoritenin antidemokratik bir zeminde meşru inşasını ifade etmektedir (Herspring, 1992).

Praetoryanist liderler, çalışanlarının gerek iş yerinde ve gerekse iş ışındaki özel yaşamları üzerinde söz sahibi olabilmektedirler. Praetoryanist lider, çalışanını hayatın her alanında denetlemek niyetindedir. 0 , çalışanlarına iş yerinde öncülük ve rehberlik ettiği kadar, onların özel yaşantılarına ve özel alanlarına girerek onları her alanda kolladığını ve koruduğunu veya onların iyiliğini her durumda düşündüğü imajını sergilemek istemektedir (Agyeman, 1988; Decalo, 1975). Böylesi bir davranışın özünde liderin iş yerinde bir kontrol ortamı yaratma çabası yer almaktadır. Astlarına yakın ve onlarla özel ilişkiler kuran bir lider, iş dışındaki özel alanlara da müdahil olmakta ve çalışanları koruyup kollayarak onlardan daha yüksek iş performansı beklemekte, ayrıca kendi lider figürünün sürekli olarak meşrulaşmasını ummaktadır (Peruzzotti, 2004). Praetoryanist bir ilişkide tarafların, sürecin başında olumlu bir tutum içinde olduğu belirlenebilir (Ben-Eliezer, 1997). Zamanla taraflar arasında yalnızca olumlu ilișkiler değil, aynı zamanda çıkara dayalı davranışlara da sıkça rastlanmaktadır (Archer, 1990). Çoğu durumda praetoryanist liderin koruyucu ve kollayıcı tavırları, çalıșan örgütten ayrıldıktan sonra devam etmemektedir (Baltacı, 2019). Diğer yandan, çalıșanların da beklentileri doğrultusunda davranarak lidere itaat ediyor gibi görünmeleri de söz konusudur (McLauchlin, 2010).

Alanyazında praetoryanist liderliğe ilişkin ilk dönem çalışmalarda kavram, alt boyutları olmayan bir yapıda incelenmiştir. Ancak praetoryanizme ilişkin kavramsal çerçeve tartışmaları geliştikçe, çeşitli alt boyutlardan bahsedilmeye başlanmıştır. 
Araştırmalar praetoryanist lider davranışının esasen: iş yerinde sürekli kontrol ortamı yaratma, antidemokratik yönetim anlayıșı sergileme, çalışanlarla özel ve yakın ilişkiler kurma, çalışanların özel hayatlarına müdahil olma, çalışanlardan saygı bekleme ve otoritesini sağlama olmak üzere farklı boyutları olduğuna vurgu yapmaktadır (Afinotan, 2014; Rizvi, 2015; Egreteau, 2016). Alanyazındaki praetoryanist liderlik araștırmaları, temelde praetoryanist liderlerin örgüte olan olumsuz etkilerini ve antidemokratik praetoryan davranış örneklerini belirleme amacıyla gerçekleştirilmiştir (Syamsuddin, 1993; De Kleijn, 2009; Hakim, 2016). Alanyazında koruyucu, işbirlikçi, otoriter ve yüksek güç mesafelerine vurgu yapan praetoryanist liderliğe çoğunlukla doğu kültürlerinde rastlanıldığını vurgulayan çalışmalar da bulunmaktadır (Perlmutter, 1994; Rizvi, 2015; Ferguson, 2017).

Alanyazında yöneticilerinin çeşitli liderlik tipleri üzerine araştırmalar yapılmaktadır. Bunun yanında çalışanların, yöneticilerini algılayışlarına ilişkin farklı araştırmalar da bulunmaktadır. Ancak praetoryanist liderliğe ilişkin ölçek geliştirme çabalarını ele alan araştırmalara rastlanılamamıştır. Türkçe alanyazında praetoryanist davranışların ölçüldüğü herhangi bir çalışma da belirlenememiştir. Praetoryanizm kavramına farklı ve özgün bir motif sunma güdüsüyle yürütülen bu çalışmanın amacı çalışanların, çalıștıkları örgütlerde bulunan yöneticilerin praetoryanist liderlik davranışlarına sahip olma düzeylerine ilişkin algılarını ölçen geçerli ve güvenilir bir ölçme aracı geliştirmektir. Çalışma sonunda belirlenecek olan ölçeğin alanyazına önemli bir katkı sunacağı düşünülmektedir. Ayrıca ölçeğin, sosyal bilimlerin farklı alanlarında kullanılabilecek esnekliğe sahip olmasının yanı sıra, liderlik çalışmalarının yapıldığı farklı disiplinlerde kullanılabileceği umulmaktadır.

\section{Yöntem}

\section{Çalışma Grubu}

Araştırmanın çalışma grubunu 2016 yılı Nisan ayı ile 2017 yılı Şubat ayları arasında İstanbul ilinin 39 ilçesinde görev yapmakta olan 983 öğretmen oluşturmaktadır. Çalışma grubunun belirlenmesinde Tabachnick ve Fidell (2001)'in istatistiksel veri analizi için belirlediği ölçütler ile Sijtsma'nın (2009) ölçekte bulunan madde sayısına göre örneklem büyüklügü belirleme ölçütleri dikkate alınmıştır. Buna göre 46 maddelik bir veri toplama aracının kabul edilebilirliği için 300 örneklem 'iyi', 500 örneklem 'çok iyi' ve 1000 örneklem 'mükemmel' olarak belirlenmiștir. Bu bağlamda araștırmanın herhangi bir sayıda örneklem belirlenmesinden ziyade, İstanbul'da çalışan tüm öğretmenleri kapsayacak genişlikte olmasına karar verilmiștir. Bu kapsamda araștırmanın hedef evreni, İstanbul'da çalışan tüm öğretmenler (148892 öğretmen) olarak belirlenmiștir. Bu denli büyük bir hedef evrenden veri toplamanın kendi içinde zorluklar barındırması sebebiyle olasılık kuramına göre örneklem belirlenmesine karar verilmiş ve hedef evrenden \%99 güvenilirlik sınırları içerisinde \%1'lik bir hata payı dikkate alınarak belirlenen örneklem büyüklüğü, 663 olarak belirlenmiștir (Altman, 1974). Ölçeğin ön uygulaması ise, ana araştırmaya katılmayan ve örneklem özelliklerini taşıyan İstanbul'un farklı ilçelerinde görev yapan 147 kişilik bir öğretmen örneklemi üzerinde yapılmıştır. Araştırmada oranlı tabakalı örnekleme tekniği kullanılarak 39 ilçeyi beş yaşam kalitesi düzeylerine göre sınıflandıran Şeker'in (2011) sınıflandırması kullanılmıștır. Araștırma, Şișli, Eyüp, Başakșehir, Beyoğlu, Adalar, Kartal, Şile, Avcılar, Bakırköy, Güngören, Kâğıthane, Silivri, Tuzla, Pendik ilçelerinde çalışan öğretmenler üzerinde yürütülmüștür. Araştırma kapsamında katılımcılara (öğretmenler), 1500 ölçek gönderilmiş, 1088'i geri dönmüştür. Bu ölçeklerden 67'si eksik veya hatalı doldurma, 38'i de aykırı değerler nedeniyle analizden çıkarılmıştır. Aykırı değerler, içinde bulunduğu örneğin diğer gözlemlerinden belirgin sapmalar gösteren değerlerdir. Aykırı değerler ölçme hatası, veri 
girişi sırasında yapılabilecek bir hata, ölçme aracının doğru çalışmaması olabileceği gibi elde edilen gözlemlerin farklı bir yığından gelmesi gibi bir durumda da ortaya çıkabilir (Teddlie ve Yu, 2007). Bu araștırmada aykırı değerler, Mahalanobis uzaklığı kullanılarak tespit edilmiştir. Örneklem büyüklüğünü karşılayan 983 ölçek analize dâhil edilmiştir. Araştırmaya katılan öğretmenlerin \%52,9'u kadındır; \%41,4'ü 31-40 yaş; \%32,9'unun mesleki kıdemi 10-15 yıl ve son olarak \%63,6'sı lisans düzeyinde eğitim almıștır.

\section{Ölçeğin Geliştirilmesi}

Praetoryanist liderlik ölçeği, okul müdürlerinin praetoryanist davranışlara sahip olma düzeylerine ilişkin öğretmen görüşlerini belirlemek amaciyla oluşturulmuştur. Alanyazındaki ilk dönem araștırmalarda praetoryanizm herhangi bir alt boyutu olmadan incelenmiștir. Sonraki dönemlerde kavram farklı alt boyutlara ayrılarak incelenmiștir. Araştırmada kullanılan "Praetoryanist Liderlik Ölçeği" alanyazındaki ilgili araștırmalardan (Afinotan, 2014; Baltacl, 2018b; 2019; De Kleijn, 2009; Hen-Tov ve Gonzalez, 2011; Rizvi, 2015; Hakim, 2016; Egreteau, 2016; Ferguson, 2017) yararlanılarak araştırmacı tarafından geliștirilmiştir. Bu ölçek geliştirme çalışması, alanyazında Baltacı (2018b; 2019) tarafından geliștirilen "Praetoryanist Davranıș Ölçeklerinin" örgütsel davranış kuramları ve liderlik tipolojileri bağlamında ele alınarak yeniden gözden geçirilmesi amaciyla yürütülmüştür.

Ölçeğin hazırlanması için çeşitli maddeler yazılarak 63 maddelik bir madde havuzu oluşturulmuştur. Birbirleriyle ilișki göstereceği tahmin edilen maddeler bir araya getirilerek bir taslak ölçek oluşturulmuştur. Hazırlanan taslak ölçek kapsam geçerliliğini sağlamak için 2 işletme alan uzmanı, 2 ölçme ve değerlendirme uzmanı, 1 örgütsel davranış alan uzmanı, 1 sosyal psikolog ve 1 eğitim yönetimi uzmanından oluşan uzman grubuna sunulmuş, alınan dönütlere göre gerekli düzenlemeler yapılmıştır. Ayrıca taslak ölçek bir dil uzmanı tarafından anlatım özellikleri bakımından incelenmiştir. Uzman görüşü sonucunda 15 madde ölçekten çıkarılmış ve taslak ölçek 48 maddeden oluşmaktadır. Praetoryanist liderlik ölçeği, likert tipi beşli dereceleme türünde hazırlanmıştır. Likert tipi ölçekte yer alan maddeler: (5) "Her zaman" ve (1) "hiçbir zaman" şeklinde puanlanmaktadır. Ölçeğin ön uygulaması ana araștırmaya katılmayan, örneklem özelliklerini taşıyan ve 2016 yılı Ocak-Şubat aylarında İstanbul'un farklı ilçelerinde görev yapmakta olan ve kartopu örneklemesi ile belirlenen 147 kişilik bir öğretmen örneklemi üzerinde yapılmıștır.

Praetoryanist liderlik ölçeğinin güvenirliği Cronbach's Alfa $(\alpha)$ ve bileşik güvenirlik katsayılarıyla belirlenmiștir. Cronbach's Alfa katsayısında ölçekte yer alan maddelerin faktör yükleri ve hata varyanslarının eşit olduğu; bileşik güvenirlik katsayısındaysa faktör yüklerinin ve hata varyanslarının farklılaştığı durumlarda kullanılması önerilmektedir (Bland ve Altman, 1997; Cortina, 1993). Bu sebeple çok boyutlu ölçeklerin güvenirlik sınamalarında bileșik güvenirlik katsayısının, Cronbach's Alfa katsayısına göre daha dengeli bir güvenirlik değeri olabileceği (Raykov, 1998; Rodriguez, Reise ve Haviland, 2016) görüşünden hareketle bu çalışmada her bir faktör için hesaplanan Cronbach's Alfa değerlerine ek olarak bileşik güvenirlik değerlerinin de belirlenmesine karar verilmiştir. Ölçeğin yapı geçerliği doğrulayıcı faktör analizi kullanılarak belirlenmiştir. Yapı geçerliliğinde öncelikle ölçümlenen model ardından yapılandırılmış model belirlenmektedir. Doğrulayıcı faktör analizinde ilk olarak ölçme modeli incelenmiștir. Bu bağlamda praetoryanist liderlik ölçeğinde yer alan değişkenlerin ilişkisi ilk düzey doğrulayıcı faktör analiziyle belirlenmiştir. Praetoryanist liderliği açıklama durumuna ilişkin yapılandırılmış model ise ikinci düzey doğrulayıcı faktör analizi ile belirlenmiștir. Bununla birlikte modelin birleşim ve ayrışım geçerliliğini sınamak için her bir alt ölçeğin ortalama varyansı açıklama değeri hesaplanmıştır. 
Açılklanan ortalama varyans değeri ölçek içindeki ikincil gizli yapıların temsil ettiği değişkenlik ortalamasını göstermektedir. Ölçeğin güvenirlik katsayıları ve açımlayıcı faktör analizi için SPSS, Doğrulayıcı faktör analizi için AMOS yazılımları kullanılmıştır.

\section{Bulgular}

Praetoryanist liderlik ölçeğinin yapı geçerliğini sınamak üzere ön uygulama sonuçları üzerinde öncelikle verilerin normal dağılımı incelenmiştir. Bu bağlamda, analiz için Kaiser-Meyer-Olkin (KMO) değeri 0.96 ve Barlett's küresellik testi anlamlı $(\mathrm{p}<0.01)$ bulunmuştur. Verilerin faktör analizi için uygun olduğu görüldüğünden daha sonra veri setine açımlayıcı faktör analizi (AFA) uygulanmıştır. Kline (2014), faktör yük değeri. 30 ve madde toplam korelasyonu. 20'den düșük olan maddelerin ölçekten çıkarılmasını önermektedir. Bu kapsamda 48 maddelik taslak ölçekten faktör yük değeri .30'dan düşük olan 15 madde ile binișik olan 8 madde çlkartılmıștır. Dört madde de madde toplam korelasyonu .20 'den daha küçük olduğu için çlkarılmıştır. Ön uygulama verilerinden hareketle faktör analizi sonucunda belirlenen 21 maddenin üç faktöre dağıldı ̆̆ belirlenmiş ve ölçeğin son hali Ek 1'de sunulmuştur. Praetoryanist liderlik ölçeğinin hesaplanan Cronbach's Alfa katsayısı ve doğrulanan Bileşik güvenirlik katsayısı değerleri Tablo 1'de görülmektedir.

\begin{tabular}{lcccc}
\hline \multicolumn{1}{c}{ Faktörler } & $\overline{\mathbf{X}}$ & ss & $\begin{array}{c}\text { Cronbach's Alfa }(\boldsymbol{\alpha}) \\
\text { Katsayısı }\end{array}$ & $\begin{array}{c}\text { Bileșik Güvenirlik } \\
\text { Katsayısı }\end{array}$ \\
\hline Yönlendiricilik & 3.21 & .53 & .87 & .91 \\
Kısıtlayıcılık & 4.03 & .41 & .88 & .92 \\
Yetkecilik & 3.59 & .76 & .91 & .93 \\
\hline
\end{tabular}

Tablo 1: Praetoryanist liderlik ölçeğinin güvenilirlik katsayıları

Tablo 1'den hareketle, praetoryanist liderlik ölçeğinin 'yönlendiricilik' boyutu için iç tutarlılık katsayısı $(\alpha) .87$ ve bileşik güvenirlik katsayısı .91; 'kısıtlayıcılık' boyutu için iç tutarlılık katsayısı $(\alpha)$.88 ve bileşik güvenirlik katsayısı .92 ve 'yetkecilik' boyutu için iç tutarlılık katsayısı $(\alpha) .91$ ve bileșik güvenirlik katsayısı .93 olarak belirlenmiștir. Praetoryanist liderlik ölçeğinin her üç alt boyutu için belirlenen güvenirlik katsayılarının tamamı bir ölçekte bulunması tavsiye edilen güvenirlik sınırı olan .70 (Cortina, 1993; Sijtsma, 2009) şartını karşılașmaktadır. Ölçeğin tamamına ilișkin toplam Cronbach's Alfa güvenirlik katsayısı .89 ve bileşik güvenirlik katsayısı .92 olarak hesaplanmıştır. Ayrıca ölçekte yer alan değişkenler arasında çoklu bağlantıllk (multicollinearatiy), içsellik (endogeneity) ve dışsallık (exogeneity) problemine rastlanmamıştır. Ölçeğin yapı geçerliliği doğrulayıcı faktör analizi ile belirlenmiştir. İki düzeyli hiyerarşik analizde her iki düzey için ilkin 21 gözlenen değişken ve 2 gizli değișken tanımlanmıștır. Bununla birlikte Tablo 3'te görüleceği üzere faktörler arası ilişkileri belirleyebilmek için hesaplanan korelasyon katsayılarının yüksek değerlerde olduğu belirlenmiştir. Bu durum faktörlerin aslında daha üst düzey bir yapıyı temsil ettiğine veya faktörlerin ayrışmadığını belirlemektedir. Bu amaçla öncelikle birinci düzey doğrulayıcı faktör analizinde ölçeğin tek boyutlu bir ölçme modeli olarak denenmesi uygun görülmüştür. Praetoryanist liderlik ölçeğinin ilk ve ikinci düzey doğrulayıcı faktör analizi sonuçları Tablo 2'de yer almaktadır. 


\begin{tabular}{lcccc}
\hline \multirow{2}{*}{ Uyum Göstergeleri } & \multicolumn{2}{c}{ Birinci Düzey } & \multirow{2}{*}{ İkinci Düzey } & Sinır Değerler \\
\cline { 2 - 3 } & Tek boyut & Üç boyut & & \\
\hline$\chi^{2}$ & 783,56 & 762,32 & 676,48 & - \\
Sd & 306 & 311 & 329 & - \\
$\chi^{2} /$ sd & 2.56 & 2.45 & 2.05 & 3 \\
$\mathrm{p}$ & 0.01 & 0.00 & 0.001 & $>0.05$ \\
CFI & 0.91 & 0.95 & 0.97 & $>0.90$ \\
NFI & 0.92 & 0.93 & 0.93 & $>0.90$ \\
SRMR & 0.09 & 0.06 & 0.05 & $<0.08$ \\
RMSEA & 0.06 & 0.04 & 0.04 & $<0.06$ \\
GFI & 0.85 & 0.86 & 0.92 & $>0.80$ \\
AGFI & 0.81 & 0.87 & 0.91 & $>0.80$ \\
\hline
\end{tabular}

Tablo 2: Praetoryanist liderlik ölçeğinin doğrulayıcı faktör analizi sonuçları

Praetoryanist liderlik ölçeğini doğrulayıcı faktör analizi sonuçlarının birinci düzey tek boyutlu modelinin uyumlu olduğu belirlenmiștir $\left(\chi^{2}(306)=783.56 ; p>0.01\right)$. Benzer şekilde üç boyutlu ölçme modelinin de uyumlu bir düzeneğe sahip olduğu söylenebilir $\left(\chi^{2}{ }_{(311)}=762.32 ; \mathrm{p}<0.01\right)$. Örneklem sayısındaki artışla doğru orantılı olarak $\chi^{2}$ değerinin anlamlı bir değere ulaşma eğiliminde olduğu varsayılmaktadır (Fox, 1983; Hoyle, 2000). Bu doğrultuda her iki ölçme modelinin uygun bir yapıda olup olmadığını belirlemek amacıyla $\chi^{2} /$ sd oranı daha uygun bir ölçüt aracı olarak düşünülmektedir. Ölçeğin hem tek ve hem de üç boyutlu modeline ilişkin $\chi^{2} /$ sd değerinin, alanyazında önerilen değeri karşıladığı ve yeterli bir uyuma sahip olduğu belirlenmiştir. Benzer şekilde uyum göstergeleri incelendiğinde, ilk düzey tek boyutlu modelin $\left(\chi^{2} / \mathrm{sd}=2.56, \mathrm{p}=0.01, \mathrm{CFI}=0.91\right.$, $\mathrm{NFI}=0.92, \mathrm{SRMR}=0.09$, RMSEA $=0.06, \mathrm{GFI}=0.85, \mathrm{AGFI}=0.81$ ) ve üç boyutlu modelin $\left(\chi^{2} / \mathrm{sd}=2.45, \mathrm{p}=0.00, \mathrm{CFI}=0.95, \mathrm{NFI}=0.93, \mathrm{SRMR}=0.06, \mathrm{RMSEA}=0.04, \mathrm{GFI}=0.86\right.$, AGFI=0.87) oldukça iyi bir uyum gösterdiği belirlenmiștir. Bununla birlikte ölçeğin üç boyutlu modeline ilișkin uyum göstergelerinin, tek boyutlu yapıya göre daha yüksek bir uyumu işaret ettiği görülmektedir. Ayrıca tek boyutlu ölçme modelinde 9 maddenin .70 seviyesinin altında (.57 ile .69) standart faktör yük değerine sahip olduğu, bunun yanında üç boyutlu modelin tüm maddelerinin standart faktör yüklerinin .70 değerinin üzerinde olduğu gözlenmiștir.

Praetoryanist liderlik ölçeğinin ikinci düzey doğrulayıcı faktör analizi sonuçları, yapısal modelin ölçümlenen verilerle oldukça iyi bir uyuma sahip olduğu söylenebilir $\left(\chi^{2}{ }_{(329)}=676.48 ; p>0.01\right)$. Karşılaştırma uyum göstergelerinin de $\left(\chi^{2} / s d=2.05, p=0.01\right.$, $\mathrm{CFI}=0.97, \mathrm{NFI}=0.93, \mathrm{SRMR}=0.05, \mathrm{RMSEA}=0.04, \mathrm{GFI}=0.92, \mathrm{AGFI}=0.91$ ) oldukça uyumlu bir modeli işaret ettiği sonucuna varılabilir. Ölçeğin ikinci düzey doğrulayıcı faktör analizi sonucunda elde edilen bulguların, ilk düzeyde elde edilen bulgulara göre daha yüksek bir uyuma sahip olduğu belirlenmiştir. Ölçeğin yapısal modeli Şekil 1'de görülmektedir. 


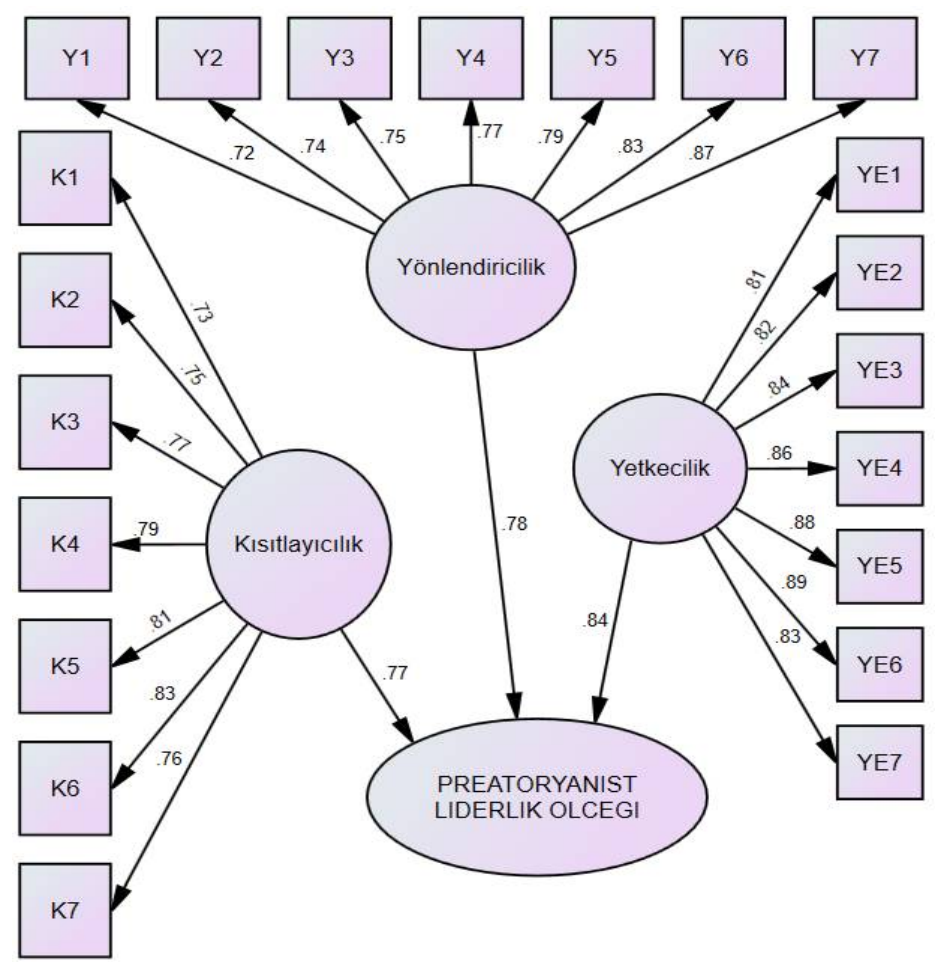

Şekil 1: Praetoryanist liderlik ölçeğinin yapısal modeli

Praetoryanist liderlik ölçeğine ilişkin modelin 'yönlendiricilik' boyutunda yer alan 7 maddenin yapısal katsayılarının 0.72 ile 0.87 arasında; 'kısıtlayıcılık' boyutundaki maddelerin yapısal katsayılarının 0.73 ile 0.83 arasında ve 'yetkecilik' boyutunda yer alan maddelerin yapısal katsayılarının 0.81 ile 0.89 arasında farklılık gösterdiği, bunun yanında tüm maddelerin $(\mathrm{p}<.01)$ düzeyinde anlamlı olduğu belirlenmiștir. Praetoryanist liderliğe ilișkin toplam varyansın, \%77'sini 'kısıtlayıcılık' boyutu, \%78'ini 'yönlendiricilik' boyutu ve \%84'ünü 'yetkecilik' boyutunun açıkladığı saptanmıștır. Her üç faktör birden ele alındığında ölçeğe ilișkin toplam varyansın \%79,66'sını açlkladığı belirlenmiștir.

Ölçeklerin birleșim geçerliliği Fornell ve Larcker (1981) tarafindan belirlenen iki temel ölçütler kullanılarak belirlenmiştir. Öncelikle ölçekte bulunan tüm maddelerin standartlaștırılmıș faktör yük değerlerinin, .70 değerini aștığı görülmektedir. Tablo 3'te Praetoryanist liderlik ölçeğinin alt boyutlarının AVE ve korelasyon katsayılarına ilişkin değerler yer almaktadır.

\begin{tabular}{lcccc}
\hline \multicolumn{1}{c}{ Faktörler } & AVE & Yönlendiricilik & Kısıtlayıcılık & Yetkecilik \\
\hline Yönlendiricilik & 0.81 & - & & \\
Kısıtlayıcılık & 0.82 & $0.72^{* *}$ & - & \\
Yetkecilik & 0.78 & $0.80^{* *}$ & $0.86^{* *}$ & - \\
\hline
\end{tabular}

** Spearman rho $\mathrm{p}<0.01$

Tablo 3: Ölçeğin alt boyutlarının AVE ve korelasyon katsayıları 
Tablo 3 incelendiğinde, Praetoryanist liderlik ölçeğinin alt boyutlarının ortalama varyanslarının (AVE) 0.5 'in üzerinde olduğu belirlenebilir. Ölçeğin alt boyutlarının korelasyonlarının, ortalama varyansın karekökünden daha düşük değerlerde belirlenmesi de (Fornell ve Larcker, 1981; Hoyle, 2000) yapısal modelin ayrışım geçerliliğine sahip olduğunun önemli bir kanıtıdır. Tablo 3'de Praetoryanizmin alt boyutları arasında yüksek düzeyde ve pozitif yönlü ilişki bulunduğu görülmektedir. En yüksek korelasyon düzeyi otoriterlik ile kısitlayıcıllk $\left(\mathrm{r}_{\mathrm{s}}=.86\right)$ alt boyutları arasında gözlenmektedir.

\section{Sonuç}

Öğretmenlerin, okul yöneticilerinin praetoryanist liderlik özelliklerine sahip olma düzeylerine ilișkin algılarını ölçmek amacıyla alanyazın ve uzman görüșleri doğrultusunda geliștirilen 'Praetoryanist Liderlik Ölçeği'nin alt boyutlara ayrılması açımlayıcı faktör analizi ile yapılmıștır. Ölçeğin güvenirliği Cronbach's Alfa Katsayısı ve Bileşik Güvenirlik Katsayısı kullanılarak hesaplanmış ve her iki katsayının da tavsiye edilen sınır değerler içerisinde yer aldığı saptanmıştır. Ölçeğin yapı geçerliliği, iki düzeyli hiyerarşik doğrulayıcı faktör analizi ile test edilmiştir. Bu amaçla ilk olarak birinci düzey analizde ölçeğin alt boyutları tek tek ve toplu olarak iki farklı modelde incelenmiștir. Böylesi iki farklı modelin kurgulanmasının sebebi alt boyutlar arasındaki yüksek ve pozitif yönlü ilișkilerin belirlenmesidir. Bu durum alt boyutların daha üst düzeyde bir yapıyı temsil edebileceği gibi, açımlayıcı faktör analizi sonucunda oluşturulan faktörlerin ayrıştırılmadığının da göstergesi olabilir. Doğrulayıcı faktör analizi sonuçları, her iki ölçme modeli için de ölçeğin veriler ile yüksek düzeyde uyum gösterdiğini belirlemiştir. Ancak ölçeğin üç alt boyutunu içeren model, tek boyutlu modele göre daha yüksek düzeyde bir uyumu işaret etmektedir. Bunun yanında, üç alt boyuta sahip olan modelde yer alan tüm maddelerin faktör yük değerlerinin .70 ve daha yüksek olması bu yapının kullanılmasında etkili olmuştur.

Sonuç olarak Praetoryanist Liderlik Ölçeğinin, 'kısıtlayıcılık', 'yönlendiricilik' ve 'yetkecilik' boyutlarından oluşan bir yapısı olduğuna karar verilmiștir. Praetoryanist liderlik ölçeğinin ikinci düzey doğrulayıcı faktör analizi sonuçları, yapısal modelin veriler ile mükemmel bir uyum içinde olduğunu göstermektedir. Yapısal modelde, 'kısıtlayıcılık', 'yönlendiricilik' ve 'yetkecilik' boyutlarının praetoryanist liderliği güçlü bir ş̧ekilde yordadığı gözlenmiştir. Böylesi bir bulgu, söz konusu üç faktörün praetoryanist liderliği oluşturduğu anlamına gelmektedir. Böylece praetoryanist liderlik için üç boyutlu yapısal modelin geçerliliği doğrulanmıştır. Praetoryanist liderlik ölçeğindeki tüm maddelerin standartlaștırılmış faktör yük değerlerinin .70 değerinin üzerinde olması, açıklanan ortalama varyansın üç faktördeki birleşim geçerliği ve alt boyutların kendi arasında yüksek düzeyde ilişki göstermesi, modelin ayrışım geçerliğine sahip olduğunu göstermektedir. Tüm bulgu ve değerlendirmelerden hareketle, Praetoryanist liderlik ölçeğinin, 'kısıtlayıcılık', 'yönlendiricilik' ve 'yetkecilik' boyutlarından oluştuğu ve çalışanların algılarına göre yöneticilerinde praetoryanist liderlik davranışlarının düzeylerini ölçebilecek, geçerli ve güvenilir bir ölçek olarak kullanılabilir niteliklere sahip olduğu ifade edilebilir.

Praetoryanist liderlik ölçeğinin geliştirilmesiyle yönetim bilimleri alanyazanına farklı bir yön kazandırıldığı ve alanyazındaki önemli bir boșluğun kapatıldığı söylenebilir. Bununla birlikte, praetoryanist liderliğin demografik değişkenlerle ilişkilerine (cinsiyet, medeni durum, gelir düzeyi vb.) ve farklı türden örgütsel davranışlar üzerindeki etkilerine yönelen daha fazla çalışmanın yapılmasına ihtiyaç duyulmaktadır. Bu çalışmada liderlik davranışı çalışmalarına yön verecek bir ölçek geliștirilerek özellikle olumsuz 
örgütsel davranışların ölçülmeye çalışıldığı alanyazına önemli bir katkı sağlanmıştır. Ancak alanyazında praetoryanizm konusu ile ilgili yeterli sayıda kuramsal ve uygulamalı çalışma olmaması, bu çalışma sonucunda önerilen modelin farklı çalışmalarla test edilmesini gerekli kılmaktadır. Praetoryanist liderlik alanyazınında ileride yapılacak çalışmaların özellikle örgüt kültürü ve farklı türden liderlik stilleri arasındaki etkileşimler gibi karşılaştırmalı çalışmalara yer veren nicel ve nitel desenlerde yapılması önerilebilir. $\mathrm{Bu}$ çalışma ile önerilen model ve yapılan geçerlik ve güvenirlik analizlerinin, gelecekte praetoryanist liderlik çalışmalarına yönelen araștırmacılara katkı sağlayacağı öngörülebilir. Ayrıca bu çalışmanın alanyazında yeni boşlukları ortaya çıkardığı sonucundan hareketle, geliştirilen praetoryanist liderlik ölçeğinin etkisinin kuramsal davranış kalıplarını açılayabileceği ve yönetim bilimleri alanyazınında farklı şekillerde tanımlanmasına yardımcı olabileceği de düşünülmektedir.

\section{KAYNAKÇA}

AFINOTAN, L. A. (2014). Praetorianism the Public Service: Analysis of the Impact and Consequences of Military Rule on Public Administration in Nigeria. Canadian Social Science, 10(2), 171.

AGYEMAN, O. (1988). Setbacks to Political Institutionalisation by Praetorianism in Africa. The Journal of Modern African Studies, 26(3), 403-435.

ALTMANN, J. (1974). Observational study of behavior: sampling methods. Behaviour, 49(3), 227-266.

ARCHER, C. I. (1990). The Royalist Army of New Spain, 1810-1821: Militarism, Praetorianism, or Protection of Interests?. Armed Forces \& Society, 17(1), 99-116.

BALTACI, A. (2018a). Örgütsel Praetoryanizm: Kavramsal Temellerin Arkeolojisi. Kırıkkale Üniversitesi Sosyal Bilimler Dergisi, 8(2), 497-522.

BALTACI, A. (2018b). Din Kültürü ve Ahlak Bilgisi Öğretmenlerinin Praetoryanist Davranış Biçimleri: İzmir Örneklemi. İnönü Üniversitesi Eğitim Fakültesi Dergisi, 19(3), 434-451.

BALTACI, A. (2019). Praetorianistic Behavior Forms: An Investigation of School Principals. Bartin Üniversitesi Egitim Fakültesi Dergisi, 8(1), 103-137.

BEN-ELIEZER, U. (1997). Rethinking the Civil-Military Relations Paradigm: the inverse relation between militarism and praetorianism through the example of Israel. Comparative Political Studies, 30(3), 356-374.

BLAND, J. M., \& ALTMAN, D. G. (1997). Statistics notes: Cronbach's alpha. Bmj, 314(7080), 572-589.

BOWMAN, K. S. (2010). Militarization, democracy, and development: The perils of praetorianism in Latin America. Penn State Press.

CORTINA, J. M. (1993). What is coefficient alpha? An examination of theory and applications. Journal of Applied Psychology, 78(1), 98-115.

DECALO, S. (1975). Praetorianism, Corporate Grievances and Idiosyncratic

Factors in Military Hierarchies. Journal of African Studies, 2(2), 247.

DE KLEIJN, G. (2009). C. Licinius Mucianus, Leader in Time of Crisis. Historia:

Zeitschrift für Alte Geschichte, (H. 3), 311-324.

DI TELLA, T. (2017). History of political parties in twentieth-century Latin

America. New York: Routledge.

EGRETEAU, R. (2016). Embedding praetorianism: soldiers, state, and constitutions in postcolonial Myanmar. In Politics and constitutions in Southeast Asia (pp. 131-153). Routledge. 
FERGUSON, Y. H. (2017). Competing Identities and Turkey's Future. European Review, 25(1), 81-95.

FORNELL, C. \& LARCKER, D. (1981). Structural equation models with unobservable variables and measurement error. Journal of Marketing Research, 18(1), 39-50.

FOX, R. J. (1983). Confirmatory factor analysis. John Wiley \& Sons, Ltd

HAKIM, M. (2016). Soeharto and the Politicization of Indonesian Islam (19681998). Journal of Indonesian Islam, 10(2), 159-180.

HALEEM, I. (2003). Ethnic and sectarian violence and the propensity towards praetorianism in Pakistan. Third World Quarterly, 24(3), 463-477.

HEN-TOV, E., \& GONZALEZ, N. (2011). The militarization of post-Khomeini Iran: praetorianism 2.0. The Washington Quarterly, 34(1), 45-59.

HERSPRING, D. R. (1992). Civil-military relations in post-communist Eastern Europe: The potential for praetorianism. Studies in Comparative Communism, 25(2), 99122.

HOYLE, R. H. (2000). Confirmatory factor analysis. Handbook of applied multivariate statistics and mathematical modeling, 465-497.

HUSSAIN, A. (1976). Ethnicity, national identity and praetorianism: the case of Pakistan. Asian Survey, 16(10), 918-930.

KLINE, P. (2014). An easy guide to factor analysis. New York: Routledge.

MAHMUD, T. (1993). Praetorianism and common law in post-colonial settings:

judicial responses to constitutional breakdowns in Pakistan. Utah L. Rev., 1225.

MCLAUCHLIN, T. (2010). Loyalty strategies and military defection in rebellion. Comparative Politics, 42(3), 333-350.

PERI, Y. (2017). Civilian Control during a Protracted War.". Politics and Society in Israel: Studies in Israeli Society Vol, 3.

PERLMUTTER, A. (1994). Arafat's Police State. Foreign Aff., 73, 8.

PERUZZOTTI, E. (2004). From praetorianism to democratic institutionalization: Argentina's difficult transition to civilian rule. Journal of Global South Studies, 21(1), 97.

PION-BERLIN, D., \& TRINKUNAS, H. (2010). Civilian praetorianism and military shirking during constitutional crises in Latin America. Comparative Politics, 42(4), 395411.

RAYKOV, T. (1998). Coefficient alpha and composite reliability with interrelated nonhomogeneous items. Applied psychological measurement, 22(4), 375-385.

RODRIGUEZ, A., REISE, S. P., \& HAVILAND, M. G. (2016). Evaluating bifactor models: Calculating and interpreting statistical indices. Psychological methods, 21(2), 137.

RIZVI, A. J. (2015). Civil-Military-Islamist Relations: An Opinion on Democracy, Islamist Militancy and Praetorianism in Pakistan.

SHAH, A. (2008). Praetorianism and terrorism. Journal of Democracy, 19(4), 1625.

SIJTSMA, K. (2009). On the use, the misuse, and the very limited usefulness of Cronbach's alpha. Psychometrika, 74(1), 107.

SYAMSUDDIN, M. D. (1993). Political stability and leadership succession in Indonesia. Contemporary Southeast Asia, 12-23.

ŞEKER, S.D., (2011), Türkiye'nin İnsani Gelişme Endeksi ve Endeks Siralamasının Analizi, DPT-SSKGM: Ankara.

TABACHNICK, B. G., \& FIDELL, L. S. (2001). Using multivariate analysis. California State University Northridge: Harper Collins College Publishers.

TEDDLIE, C., \& YU, F. (2007). Mixed methods sampling: A typology with examples. Journal of mixed methods research, 1(1), 77-100. 
UZGEL, I. (2003). Between Praetorianism and Democracy: The Role of the Military in Turkish Foreign Policy. Turkish Yearbook of International Relations, 34, 177212.

Ek 1. Praetoryanist Liderlik Ölçeği

\begin{tabular}{|c|c|c|c|c|}
\hline 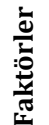 & Md. No & & $\begin{array}{l}\text { Fak. } \\
\text { Yük } \\
\text { Değ. }\end{array}$ & $\begin{array}{l}\text { Md. } \\
\text { Top. } \\
\text { Kor. }\end{array}$ \\
\hline \multirow{7}{*}{ 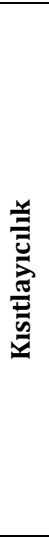 } & K1 & $\begin{array}{l}\text { Yöneticim, kendi değer, ilke ve kurallarına uymamızı } \\
\text { ister. }\end{array}$ & .702 & .789 \\
\hline & K2 & $\begin{array}{l}\text { Yöneticim ișe geç gelme, sigara kullanma vb. } \\
\text { alış̧kanlıkları olan çalışanlara karşı çeşitli } \\
\text { kısıtlamalar getirir. }\end{array}$ & .696 & .682 \\
\hline & K3 & $\begin{array}{l}\text { Yöneticim çalışanları disipline etmek için katı bir } \\
\text { kontrol sağlamaya çalıșır. }\end{array}$ & .682 & .656 \\
\hline & K4 & $\begin{array}{l}\text { Yöneticim kendi emirlerinin sorgulanmasını ve karşı } \\
\text { çlkılmasını istemez. }\end{array}$ & .679 & .663 \\
\hline & K5 & $\begin{array}{l}\text { Yöneticim kendisi ile ters düşen veya kendisini } \\
\text { eleștiren çalıșanların bazı haklardan yararlanmasını } \\
\text { engeller veya onları cezalandırır. }\end{array}$ & .674 & .659 \\
\hline & K6 & $\begin{array}{l}\text { Yöneticim kendi ilkelerine göre ve kendi istediği gibi } \\
\text { çalıșmamızı ister. }\end{array}$ & .671 & .657 \\
\hline & K7 & $\begin{array}{l}\text { Yöneticim, çalışma alanlarımızı (oda, banko vb.) } \\
\text { kişiselleştirmemizi istemez. }\end{array}$ & .662 & .643 \\
\hline \multirow{7}{*}{ 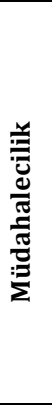 } & M1 & Yöneticim, çalıșanlar arasındaki sorunlara karıșır. & .879 & .863 \\
\hline & M2 & $\begin{array}{l}\text { Yöneticim, çalışanların giyim tarzlarına müdahale } \\
\text { eder. }\end{array}$ & .871 & .854 \\
\hline & M3 & $\begin{array}{l}\text { Yöneticim, çalışanların özel yaşantılarına müdahale } \\
\text { eder. }\end{array}$ & .869 & .852 \\
\hline & M4 & $\begin{array}{l}\text { Yöneticim, iş arkadaşlarımla ilişkilerime müdahale } \\
\text { eder. }\end{array}$ & .868 & .850 \\
\hline & M5 & Yöneticiden habersiz bir iș yapılması imkânsızdır. & .867 & .851 \\
\hline & M6 & $\begin{array}{l}\text { Yöneticim, çalışanları sürekli kontrol ederek } \\
\text { uyarılarda bulunur. }\end{array}$ & .761 & .743 \\
\hline & M7 & $\begin{array}{l}\text { Yöneticim, çalışanların ast ve üstleriyle olan } \\
\text { ilișkilerine müdahale eder. }\end{array}$ & .752 & .733 \\
\hline \multirow{7}{*}{ 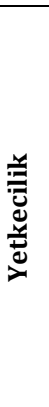 } & YE1 & $\begin{array}{l}\text { Yöneticim karar alırken kimseye danışmaz, kararları } \\
\text { tek başına alır. }\end{array}$ & .823 & .919 \\
\hline & YE2 & $\begin{array}{l}\text { Yöneticim, çalışanlardan kendisine koşulsuz itaat } \\
\text { etmelerini bekler. }\end{array}$ & .813 & .930 \\
\hline & YE3 & $\begin{array}{l}\text { Yöneticim, iş yerindeki her şeyden kendisinin } \\
\text { sorumlu olduğunu düşünür. }\end{array}$ & .808 & .940 \\
\hline & YE4 & $\begin{array}{l}\text { Yöneticim, çalışanların inisiyatif kullanmasını, } \\
\text { bağımsız çalışmasını istemez. }\end{array}$ & .806 & .918 \\
\hline & YE5 & Yöneticim, eleștirilmeyi sevmez. & .712 & .701 \\
\hline & YE6 & Yöneticim, kendisine bağımlı olunmasını ister. & .601 & .636 \\
\hline & YE7 & $\begin{array}{l}\text { Yöneticim, kendisine itiraz eden çalışanları kurumda } \\
\text { barındırmaz. }\end{array}$ & .511 & .507 \\
\hline
\end{tabular}




\section{Summary}

Praetorianism is a concept that considers the mere well-being of the periphery by acting as a guardian or custodian. Furthermore, praetorianism is defined philosophically as protecting someone's goodness, without his intervention, to the extent of limiting his freedom. Praetorianism is the involvement of a person in their lives, focusing on the benefits or advantages of the people except him/her, protecting them at the expense of life, and going through various decisions or arrangements, ignoring people's desires and thoughts. At this point, the belief that the decisions and regulations took and the methods of protection are the right choices for the person is examined together with the concept of praetorianism. Praetorianism also includes inadequate perceptions and criticism of persons outside him/her. Criticism in Praetorianism is often a habit of guardianship; as the level of criticism increases, the possibility of interfering with the freedoms is also increasing. In the name of others, the praetorianist (guardian) is the person who implements the protection action for their well-being; the person whom the praetorianistic thinks is protected is called 'praetoriad'.

Praetorianistic leadership is reminiscent of the domination of a senior soldier over the army. Based on attitudes and behaviors such as respect, loyalty, and obedience to the soldier figure, praetorianistic leadership asks the employees of the organization to behave in a way that justifies military control against the leaders and leaders of the organization. Praetorianistic leadership refers to the harmonization of strict discipline and authority with various attitudes and behaviors, and the legitimate construction of authority on an antidemocratic ground.

The aim of this study, which is carried out with the motive of presenting a distinctive and unique motif to the concept of praetorianism, is to develop a valid and reliable measurement tool that measures the perceptions of teachers about the level of praetorianistic leadership behaviors of the administrators in the schools they work. It is thought that the scale, which will be determined at the end of the study, will make an important contribution to the literature. The study group consists of 983 teachers working in 39 districts of Istanbul. In order to prepare the scale, various items were written and a pool of 63 items was formed. A draft scale was formed by bringing together the items that are expected to relate to each other. The draft scale was presented to expert opinion; As a result of the expert opinion, 15 items were removed from the scale and the draft scale consisted of 48 items. The Praetorianistic leadership scale was prepared in the Likert type five-point scale. Likert-type items are scored as "(5) Always and (1) Never".

The reliability of the Praetorians leadership scale was determined by Cronbach's Alpha $(\alpha)$ and compound reliability coefficients. The construct validity of the scale was determined by using confirmatory factor analysis. However, the model, which includes three sub-dimensions of the scale, indicates a higher level of fit than the one-dimensional model. In addition, the factor load values of all items in the model having three sub-dimensions .70 and higher were effective in using this structure.

As a result, it was decided that the Praetoryanist Leadership Scale had a structure consisting of 'restrictive', 'directive' and or authoritarianism 'dimensions. The results of the second level confirmatory factor analysis of the Praetorians' leadership scale show that the structural model is in perfect agreement with the data. In the structural model, it was observed that the dimensions of 'restrictiveness', 'directionality' and or authoritarianism strongly predicted praetorianistic leadership. Such a finding means that these three factors constitute praetorianistic leadership and can be used as a reliable scale. This study, which will give a different direction to the praetorianistic leadership literature, can be concluded that an important gap in the literature has been closed. 